\title{
MSCA based Deep Recurrent Neural Network for Statistics Risk Management in Construction Projects
}

\author{
J. SENTHIL ${ }^{*}$, M. MUTHUKANNAN ${ }^{2}$, Mariusz URBAŃSKI ${ }^{3}$, Marcin STEPIEN $^{4}$ and \\ Grzegorz KADZIELAWSKI
}

Authors' affiliations and addresses:

${ }^{1}$ Research Scholar, Department of Civil

Engineering, Kalasalingam Academy of Research and Education, Krishnankoil-626126, Tamil

Nadu, India

e-mail senthil.j@klu.ac.in

${ }^{2}$ Professor, Department of Civil Engineering, Kalasalingam Academy of Research and Education, Krishnankoil-626126, Tamil Nadu,

India

e-mail m.muthukannan@klu.ac.in

${ }^{3}$ Ph.D. Road and Bridge Research Institute, Instytutowa str 1. 03-302 Warsaw, Poland e-mail murbanski@interia.eu

Ph.D. Faculty of Management, Częstochowa University of Technology, Armii Krajowej 19B, 42-201 Częstochowa, Poland

e-mail marcin.stepien@wz.pcz.pl

${ }^{5} \mathrm{Ph}$.D. Department of Management, Faculty of Applied Sciences, WSB University, Cieplaka 1c, 41-300 Dąbrowa Górnicza, Poland

e-mail: gkadzielawski@wsb.edu.pl

\section{*Correspondence:}

J. Senthil, Research Scholar, Department of Civil Engineering, Kalasalingam Academy of Research and Education, Krishnankoil-626126, Tamil Nadu, India

e-mail senthil.j@klu.ac.in

How to cite this article:

Senthil, J., Muthukannan, M., Urbański, M., Stępień, M. and Kądzielawski, G. (2021) MSCA based Deep Recurrent Neural Network for Statistics Risk Management in Construction Projects. Acta Montanistica Slovaca, Volume 26 (3), 481-497

DOI:

https://doi.org/10.46544/AMS.v26i3.08

\begin{abstract}
Risk management plays a vital role in various construction activities to maximise construction profitability and reduce the loss of construction projects. Managing risk in construction projects is considered the most significant process in achieving the objectives in terms of quality, cost and time. Also, it is necessary to prioritise and identify the most probable risk that occurs during construction projects. Due to the unanticipated risk, around $40 \%$ of construction projects are dropdown in developing countries. This paper aims to develop and identify the project delay risk at a minimum duration of time and cost. Our paper comprises of five major phases: Identification of risk source and its factors, Systemization and Preprocessing of the dataset, Analysis of dataset constraints, Sensitivity data computation, and Tool selection using DRNN-MSCA to determine the risk, thereby establishing an effective and accurate prediction analysis. Here, the machine learning algorithm, namely the Deep Recurrent Neural Network (DRNN) and the Modified Sine Cosine Optimization Algorithm (MSCA), is integrated to minimise the inter-dependence and the complexity of the construction delay. The 5-point Likert scale computes the probability and the variables impact by the measures from very low to a very high level. Finally, the performance of the proposed approach is calculated and compared with a few other existing approaches such as ANN (Artificial Neural Network), RF-GA (Random forest and Genetic algorithm) and ML (Machine learning). The results reveal that the proposed approach provides a superior accuracy performance is $81.65 \%$, with less cost and time delay.
\end{abstract}

\section{Keywords}

Construction project, risk management, DRNN, MSCA, prediction analysis, time, cost 


\section{Introduction}

The construction projects comprise various grouping endeavours associated with engineering-based construction works of diverse classes or categorisations. It also involves both a dynamic and complex atmosphere that measures the impact of the most probable instances of risk and uncertainty (Srinivasan \& Rangaraj, 2020). At the present time, project management has been utilised extensively across numerous industrial sectors. In the context of defining project management, "A project is considered as a transient or short term attempt that consists of a distinctive point of departure and a terminal or destination point that results in remarkable product or service". There are a few limitations that demonstrate the project management, which includes time, scope, quality, cost, risk and resources (Leslie Appiah, 2020; Al-Subaie et al., 2021). Due to certain limitations, the organisation fails to perform their project within the framework and to overcome such shortcomings, the organisation must spot out the risk of the project, which includes quality, scope, time, cost etc. that creates a momentous impact during selecting a contractor and the assigning of the project to the contractor (Fakhratov et al., 2020). The process involved in project management comprises of a distinct procedure set that includes quantitative and qualitative risk performances, controlling the risk factor, identification of potential risk as well as the preparation of risk plan responses (Nawaz et al., 2019; Vaníčková \& Szczepańska-Woszczyna, 2020).

Risk management plays a vital role in various construction activities to maximise construction profitability and to reduce the loss of construction projects. On the other hand, the construction risk influences the quality, cost and time duration of the project. Therefore, it is necessary to prioritise and identify the most probable risk occurring during the construction projects (Ortiz, Pellicer \& Molenaar, 2019; Velumani, Nampoothiri \& Mariusz, 2021). Numerous surveys demonstrated by various research scholars were conducted between the managerial personnel, engineers and contractors to analyse the risk while constructing projects. Risk management in terms of construction projects identifies the major factors that potentially influence the performances that result in probable losses, namely the scheduling, workmanship and quality (Adeleke et al., 2019). The organisation's main intention is to identify the risk and implement various corrective measures to mitigate various potential impacts associated with them (Rahman \& Adnan, 2020). Risk can be reduced or even eliminated in companies by adhering to the principles of sustainable business development (Kasych and Vochozka, 2018). According to Kliestik et al. (2020), earning management is responsible for maximising short-term and long-term profit. Earning management must cooperate with risk management to achieve their aims (Bacik et al., 2019; Dvorsky et al., 2021).

In addition to this, the technique that estimates and identifies the risk based on personal and property is referred to as the risk assignment. Although the construction project comprises of numerous variables, therefore, the correlations, dependency, and causality seem difficult to determine (Yazdani et al., 2019). Because of diverse activities, construction projects have become more risky and complex between various companies worldwide. On the other hand, the construction projects undergo numerous risk factors during working conditions, construction practices, political conditions among host and home countries, as well as mixed cultures. Thus, risk management plays a vital role in decision making progression during the construction of the project (Abazid \& Harb, 2018; Uğural, Giritli \& Urbański, 2020). The construction sector also comprises of various stack holders that create a very big challenge in the industry. The project failure during the construction requires huge time and cost, and it must be assessed and evaluated with respect to various scenarios (Lam \& Siwingwa, 2017).

This paper proposes five major phases: Identification of risk factors and its source that comprises of Proprietor, Resource Person, Construction Contractor, Layout model, Labour, Stocks and Resources, Apparatus, Time Delay and Cost, Climate as well as External Risk, Systemization and Pre-processing of the dataset, Analysis of dataset constraints, Sensitivity data computation, and Tool selection using DRNN-MSCA to determine the risk thereby establishing an effective and accurate prediction analysis at minimum time and cost. The contribution and organisation of the paper are obtained in the following section.

- Developing five various phases to determine the risk and to minimise the inter-dependence and the complexity of the construction delay.

- Integrating DRNN-MSCA to establish an effective and accurate prediction analysis at minimum time and cost.

- Comparing our proposed approach with other existing approaches to evaluate the effectiveness of the system.

The following section provides the organisation of our work. Section 2 depicts the summary of various literature works regarding risk management on construction projects. Section 3 describes the proposed methodology using five different phases. Also, the DRNN-MSCA algorithm is integrated for the effective prediction of risk. In section 4, the results of the proposed approach and the comparative analysis of other existing approaches are presented. Finally, section 5 concludes the article. 


\section{Literature Review}

Several research scholars conducted a number of researches and experiments regarding risk management on construction projects. In order to gain a better understanding, the summary of a few existing research works are delineated in the following section.

The study by Burduk et al. (2021) demonstrated in the Failure Mode and Effect Analysis (FMEA) to determine the causes and effects of failures and determine the corrective actions. This approach has given an idea for Deep Recurrent Neural Network (Burduk et al., 2021).

The research conducted by Siwiec and Pacana (2021), Vaněk et al. (2020) and Wolniak (2019) demonstrated in the Failure Mode and Effects Analysis (FMEA). The analysis implies that discontinuous technology involves more risks than continuous conveyance. This finding is also the answer to the research question asked by the authors in the Introduction. However, the higher degree of risk in discontinuous technology does not necessarily mean that it cannot be used when deciding on overburdened transport technology (Vaněk et al., 2020).

The study by Mustaffa et al. (2020) demonstrated the integration of a three-dimensional building information model (3D-BIM) to identify risk management in the construction sectors. The evaluation metrics obtained in this approach was rank, mean and RII weightage score that evaluates the risk in terms of quality, time and cost. The experimental analysis was conducted with respect to the above three parameters, and the results revealed that the 3D-BIM approach identifies the risk at the early period with enhanced coordination. But this approach failed to identify a large percentage of risk using 3D-BIM analysis (Mustaffa et al., 2020). Vrbka, Šuleř and Horák (2019) analysed the construction sector in the Czech Republic by using ANN to identify the leaders in this industry.

A novel approach for risk management was developed by Mahmoudi et al. (2020), and it revealed the utilisation of three different approaches, namely the Best Worst (BW) approach, Grey Relation (GR) analysis and Analytic Hierarchy $(\mathrm{AH})$ process for risk minimisation. Score, rank, distinguishing coefficient, grey relation grade were the performance measures employed in this approach. This approach failed to define significant factors involved in the identification of risk for construction projects (Mahmoudi et al., 2020).

Zhang and Mohandes (2020) research demonstrated Occupational Health and Safety in green building construction projects using a Holistic Z-numbers-based Risk Management (HZRMS) approach. The performance metrics employed in this approach are Magnitude, risk weight, safety risk, rank, frequency. This approach is involved in identifying the critical safety risk during the construction of projects, but the implementation is complex (Zhang \& Mohandes, 2020). According to Krulický and Horák (2019), buildings can be considered good investment assets, so risk management in construction projects is also very important for real estate investors.

A critical success factor (CSF) framework for effective implementation of risk management was proposed by Bu Qammaz and AlMaian (2020). Rank, cluster, time were the evaluation measures employed in this approach. This approach provides minimum risk in the construction phase but is less effective (Bu Qammaz \& AlMaian, 2020).

Integrated risk management framework for tolerance-based mitigation strategy decision that supports modular construction projects. Coefficient value, risk impact, input percentile were the performances that are evaluated in this approach. The experimental results were conducted, and the analysis revealed that this approach was provided with enhanced modularisation performances with a low rate of accuracy (Enshassi et al., 2019).

Innovations are the driving force of economic life in countries (Gavurova et al., 2021a; Gavurova et al. 2021b). According to Jiříček and Dostálová (2018), research and innovation in the business sector require EU investment to support the competitiveness of small and medium-sized enterprises. The development of supply chain risk management approaches for construction projects was proposed by the researchers (Shojaei \& Haeri, 2019). They developed a ground theory framework to enhance the performances and to identify the risk mitigation scenario. The evaluation metrics employed in this approach was weight, rank, supply chain risk. In addition, this approach failed to address managerial issues. According to Rowland and Šuleř (2019), the level of risk can be regulated using sub-system management of organisational culture. The diversification of specific tasks and the associated diversification of responsibilities for their fulfilment ultimately have a positive effect on reducing the risks associated with a particular project.

Chatterjee et al. (2018) proposed a hybrid MCDM technique for risk management in construction projects. There are three different types of risk employed in this approach, namely the external risk, internal risk and project risk. The experimental analysis was conducted, and the analysis reveals that this approach consists of high sensitivity and reliability values and failed to determine the hidden risk (Chatterjee et al., 2018).

Mhetre et al. (2016) utilised a work breakdown structure (WBS), and risk breakdown structure (RBS) to establish an effective risk management system. The performance measures employed in this approach are rank, and weightage score. This approach was provided with a minimum value of risk, but the implementation seems complex in this approach (Mhetre et al., 2016).

Hamzaoui et al. (2019) developed an organised method of risk analysis that employed two different approaches, namely MADS and MOSAR approach. Cost, time, the quality percentage was the metrics employed 
in this approach. In addition to this, organised approaches are employed in the easy identification of risk. But this approach failed to consider the safety barrier during the risk management process (Hamzaoui et al., 2019).

Wang et al. (2018) developed a meta-network-based risk evaluation and control method for industrialised construction projects. Risk factors, cost, time, rate of probability were the performance measures employed in this approach. The analysis revealed that this approach was provided with a high rate of feasibility. But the effectiveness of the system is very low, which is the major drawback of this approach. The summary of the existing literature works is discussed in Table 1.

Table. 1: Summary of existing related works

\begin{tabular}{|c|c|c|c|c|}
\hline References & Techniques/ Approaches & Evaluation Metrics & Merits & De-Merits \\
\hline $\begin{array}{c}\text { (Burduk et al., } \\
\text { 2021) }\end{array}$ & $\begin{array}{c}\text { Failure Mode and Effect } \\
\text { Analysis (FMEA) }\end{array}$ & $\begin{array}{l}\text { Risk assessment for the } \\
\text { loading and haulage } \\
\text { processes with the use of } \\
\text { ANN }\end{array}$ & $\begin{array}{l}\text { Grouped causes of the } \\
\text { problem }\end{array}$ & $\begin{array}{l}\text { Limited to liner model } \\
\text { project. }\end{array}$ \\
\hline $\begin{array}{c}\text { (Mustaffa et al., } \\
\text { 2020) }\end{array}$ & 3D-BIM Model & $\begin{array}{l}\text { Identification of early risk } \\
\text { and enhanced coordination }\end{array}$ & $\begin{array}{l}\text { Rank, mean, RII weightage } \\
\text { score }\end{array}$ & $\begin{array}{c}\text { An only small percentage } \\
\text { of risk is identified }\end{array}$ \\
\hline $\begin{array}{l}\text { (Mahmoudi et al., } \\
\text { 2020) }\end{array}$ & BWM, GRA, AHP & Minimum potential risk & $\begin{array}{l}\text { Score, rank, distinguishing } \\
\text { coefficient, grey relation } \\
\text { grade }\end{array}$ & $\begin{array}{l}\text { Failed to define } \\
\text { significant factors }\end{array}$ \\
\hline $\begin{array}{c}\text { (Zhang \& } \\
\text { Mohandes, 2020) }\end{array}$ & HZRMS approach & $\begin{array}{l}\text { Critical safety risk } \\
\text { identification }\end{array}$ & $\begin{array}{c}\text { Magnitude, risk weight, } \\
\text { safety risk, rank, frequency }\end{array}$ & $\begin{array}{l}\text { Complex during } \\
\text { implantation }\end{array}$ \\
\hline $\begin{array}{l}\text { (Bu Qammaz \& } \\
\text { AlMaian, 2020) }\end{array}$ & CSF framework & $\begin{array}{l}\text { Minimum risk in the } \\
\text { construction phase. }\end{array}$ & Rank, cluster, time & $\begin{array}{c}\text { Ineffective risk } \\
\text { management }\end{array}$ \\
\hline $\begin{array}{c}\text { (Enshassi et al., } \\
\text { 2019) }\end{array}$ & $\begin{array}{c}\text { Symmetric risk } \\
\text { management framework }\end{array}$ & $\begin{array}{c}\text { Enhanced modularisation } \\
\text { performances }\end{array}$ & $\begin{array}{l}\text { Coefficient value, risk } \\
\text { impact, input percentile }\end{array}$ & Low accuracy \\
\hline $\begin{array}{c}\text { (Shojaei \& Haeri, } \\
\text { 2019) }\end{array}$ & Ground theory approach & $\begin{array}{c}\text { Enhanced performance in } \\
\text { identifying the risk } \\
\text { mitigation scenario }\end{array}$ & $\begin{array}{c}\text { Weight, rank, supply chain } \\
\text { risk }\end{array}$ & $\begin{array}{l}\text { Failed to address } \\
\text { managerial issues }\end{array}$ \\
\hline $\begin{array}{c}\text { (Chatterjee et al., } \\
\text { 2018) }\end{array}$ & $\begin{array}{l}\text { Multi-criteria decision- } \\
\text { making process }\end{array}$ & $\begin{array}{l}\text { High sensitivity and } \\
\text { reliability }\end{array}$ & $\begin{array}{c}\text { Internal, external and project } \\
\text { risk }\end{array}$ & $\begin{array}{c}\text { Hidden risks are } \\
\text { undetermined }\end{array}$ \\
\hline $\begin{array}{c}\text { (Mhetre et al., } \\
\text { 2016) }\end{array}$ & WBS, RBS & Minimum risk failure & Rank, weightage score & $\begin{array}{l}\text { Difficult to implement } \\
\text { and high time } \\
\text { consumption } \\
\end{array}$ \\
\hline $\begin{array}{c}\text { (Hamzaoui et al., } \\
\text { 2019) }\end{array}$ & MADS, MOSAR & $\begin{array}{l}\text { Easy identification of risk } \\
\text { failures } \\
\end{array}$ & $\begin{array}{c}\text { Cost, time, quality } \\
\text { percentage }\end{array}$ & $\begin{array}{c}\text { Failed to consider safety } \\
\text { barrier }\end{array}$ \\
\hline $\begin{array}{c}\text { (Wang et al., } \\
\text { 2018) }\end{array}$ & Meta network analysis & High rate of feasibility & $\begin{array}{l}\text { Risk factor, cost, time, rate } \\
\text { of probability }\end{array}$ & ineffective \\
\hline
\end{tabular}

\section{Proposed Methodology}

This section comprises of five major phases: Identification of risk source and its factors, Systemization and Pre-processing of the dataset, Analysis of dataset constraints, Sensitivity data computation, and Tool selection using DRNN-MSCA to determine the risk, thereby establishing an effective and accurate prediction analysis. In addition to this, the machine learning algorithm, namely the Deep Recurrent Neural Network (DRNN) and the Modified Sine Cosine optimisation Algorithm (MSCA), is integrated to minimise the inter-dependence and the complexity of the construction delay. The overall architectural diagram for the DRNN-MSCA based prediction of risk delay in the construction project is represented in Fig. 1.

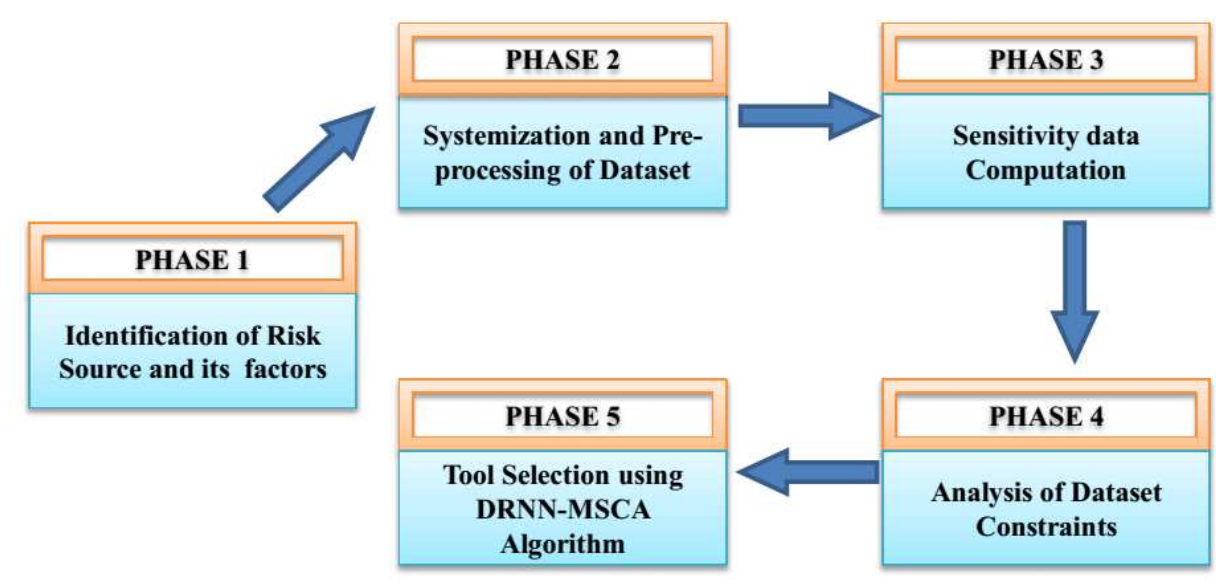

Fig.1. DRNN-MSCA based prediction of risk delay in construction project 


\section{Phase 1: Identification of risk source and its factors}

The initial phase involves the determination of appropriate risk sources and their factors. Here the risk factors are obtained from diverse surveys and are adopted subsequently in our present research. Here, the risk factors employed in this paper relate to Proprietor, Resource Person, Construction Contractor, Layout model, Labour, Stocks and Resources, Apparatus, Time Delay and Cost, Climate, and External Risk. Eventually, the lists of each individual risk factor are determined from various risk source categorisations. In addition to this, such types of risks are recognised from various research articles regarding construction methodologies, engagement of the stakeholder, geographical conditions, availability of resources, political situations etc. The following section elaborates on the types of risk and their identified risk factors.

Proprietor: The risk factors, namely lack in the planning of the project, progress delay, poor coordination among the resource person and the proprietor, progress delay, conflict among joint ownership, changing of orders, work suspension.

Resource Person: Postponement during reviewing, inspecting, approving significant variations, an argument among design engineer and consultant, lack of experience by the consultant, communication lacking among the resource person and the proprietor.

Construction Contractor: Poor site supervision and management, repeated changing of contractors, very slow mobilisation of site, rework because of construction errors, lack while investigating sites, ineffective planning of the project, argument among Construction contractor and proprietor or resource person.

Layout model: Lacking team experiences while designing, delay in designing of construction based documents, incomplete drawings, disagreement with the owner.

Labour: Inadequate labour, inexperienced labour, labour shortage, the argument between the labours, unqualified labour.

Stocks and Resources: Damage of sorted resources, construction material shortage, lack of resources, change in specification during construction, variation in the type of materials.

Apparatus: Equipment shortage, Low equipment efficiency, lacking high technological equipment, repeated breakdown of equipment, Low productivity equipment, Improper functioning of the equipment.

Time Delay and Cost: Permission delay from the municipality, delay in getting approval from government sectors, delay in obtaining services from various resources such as electricity, telephone and water, price fluctuations, too short of original contract duration.

Climate: Risk occurs due to unexpected sub-surface and surface conditions, adverse weather conditions like storm, heavy rain and wind etc.

External: Accident occurrences during the construction of sites, a dispute among neighbours, mistakes in contract documents, inefficient penalty delay, communication lack among projects.

\section{Phase 2: Systemization and Pre-processing of the dataset}

The data employed in developing the predictive tool analysis comprises of 100 construction projects from 48 firms that experienced diverse degrees of time delay. The specific project linked with various data variables is represented by the data record in the specified dataset. In order to evaluate the illustrated dataset, the initial meeting and the project type is sorted. In accordance with the records of risk sources and factors, the index scales are categorised into two categories that are mentioned in Tables 2 and 3. The initial scale narrates the consequences of the severity towards affecting the objective of the project time. Secondly, the recurrence frequency is related to the entire project. Then the whole risk is computed by multiplying the time overrun (TO) of the corresponding two score values (Xia et al., 2017).

Tab. 2. Index scale for Consequence severity

\begin{tabular}{c|c}
\hline \multicolumn{2}{c}{ Consequence Severity } \\
\hline Index range & Statement \\
\hline 0.05 & Negligible TO \\
0.25 & $<10 \% \mathrm{TO}$ \\
0.45 & $10-20 \% \mathrm{TO}$ \\
0.65 & $20-30 \% \mathrm{TO}$ \\
0.85 & $>30 \% \mathrm{TO}$ \\
\hline
\end{tabular}

Tab. 3. Index scale for recurrence frequency

\begin{tabular}{c|c}
\hline \multicolumn{2}{c}{ Recurrence Frequency } \\
\hline Index range & Statement \\
\hline 0.15 & Exceptional \\
0.35 & unusual \\
0.55 & Lessen \\
0.75 & regular \\
0.95 & Widely prevalent \\
\hline
\end{tabular}




\section{Phase 3: Analysis of dataset constraints}

During the gathering of data, it is necessary to consider numerous limitations and constraints. Initially, the data gathered should relate to the construction, design, operation and finance based entities. Secondly, the data gathered should consider only the data regarding the Construction project and not the categorisation of the construction projects. Thirdly, the size of the project is considered in which the data assembles the duration of the contract for approximately two to three years. Finally, the data is gathered only from the project Construction in which the time overrun is assumed to be greater than zero. In addition to this, the quality and integrity of the data are ensured by adopting numerous contemplated considerations. It is also necessary to consider the project containing adequate evidence and records with reliable data.

\section{Phase 4: Sensitivity data computation}

In order to gain a better understanding, it is necessary to evaluate the exploratory data analysis from the gathered data records. For facilitating the performances, the exploratory data analysis is intended to provide the three most significant insights, namely smoothed frequency curves and variable frequency counts, the sensitivity analysis exploring the dependencies of time overrun in accordance with various risk sources as well as the sensitivity analysis exploring the dependencies of time overrun in accordance with various risk sources among themselves.

\section{Phase 5: Tool selection using DRNN-MSCA}

In predictive data analysis, machine learning is considered as one of the most promising tools that integrate the complex datasets from various sectors, namely data mining, artificial intelligence, analysis of the database, patterns of interest, statistics, pattern recognition etc. (Tixier et al., 2017; Bhatt et al., 2021). Machine learning and its prediction ability were used in various research. Krulický, Kalinová a Kučera (2020) use machine learning for prediction USA export to the People's Republic of China. Also, Vrbka et al. (2020) use machine learning of ANN to estimate the development of the trade balance between the USA and the People's Republic of China. Here, in this paper, the DRNN along with MSCA is employed in predicting the risk that is explained in the following section.

\section{Deep Recurrent Neural Network (DRNN)}

Fig.2 represents the structural diagram of DRNN. In general, the DRNN comprises of three various layers, namely the input layer, output layer and a set of hidden layers. The recurrent connection or a recurrent link is found in between the hidden layers. The output of the previous step is provided as the input of the subsequent step, and the iteration process is continued with respect to the information obtained from the hidden state. The major merit of employing the DRNN classifier is that the DRNN operates more effectively under the input length of various features (Pune Borhade \& Nagmode, 2020). The mathematical formulations involved in DRNN are expressed in the following section.

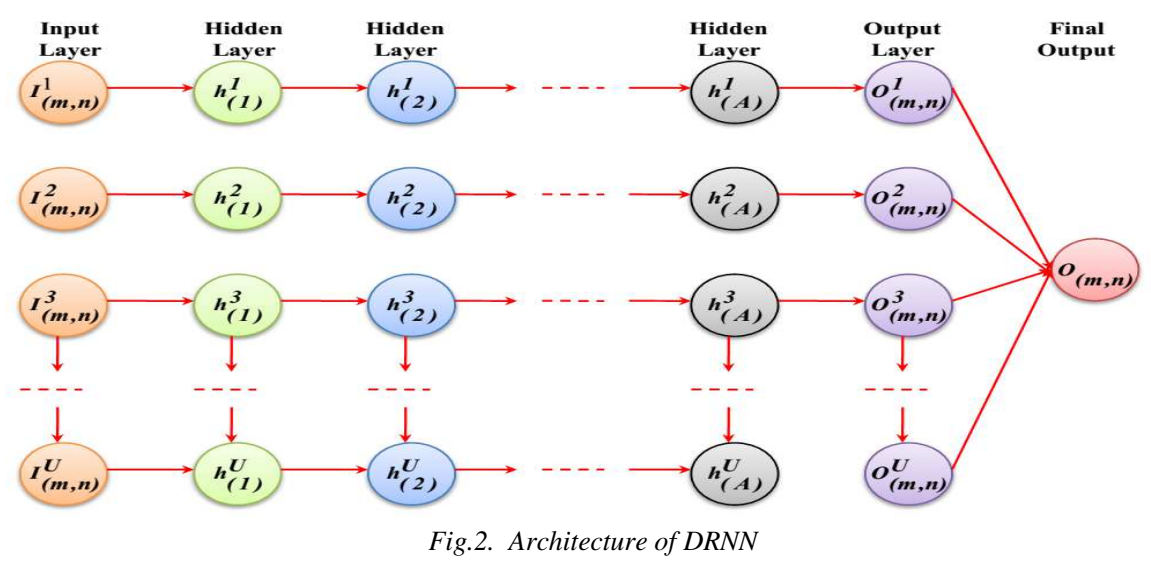

The DRNN that defines the input and the output vector with respect to the $m^{\text {th }}$ layer at the $n^{\text {th }}$ time is represented in the following section.

$$
\begin{gathered}
\text { Inputvector }: I_{(m, n)}=\left\{I_{(m, n)}^{1}, I_{(m, n)}^{2}, . . I_{(m, n)}^{A}, . . I_{(m, n)}^{U}\right\} \\
\text { Outputvector }: O_{(m, n)}=\left\{O_{(m, n)}^{1}, O_{(m, n}^{2}, . . O_{(m, n)}^{A}, \ldots O_{(m, n)}^{U}\right\}
\end{gathered}
$$


From equations (1) and (2), the arbitrary number and the total number of units of the $m^{\text {th }}$ layer are represented by $A$ and $U$, respectively. Then the input propagation weight and the recurrent weight with respect to the $m^{\text {th }}$ layer are derived in the following section.

$$
\begin{gathered}
\text { Input propagation weight: } I_{(m)}^{W} \in X^{U \times \alpha} \\
\text { Recurrent weight: } R_{(m)}^{W} \in X^{U \times \beta}
\end{gathered}
$$

From Equations (3) and (4), $\alpha$ and $\beta$ signify the total number of units and the arbitrary unit number of the ( $m$ $-1)^{\text {th }}$ layer, respectively. Then the set of weights is represented as $X$. Therefore, the input and the output vector component with respect to the arbitrary layer are represented as follows.

$$
I_{(m, n)}^{A}=\sum_{H=1}^{\alpha} L_{m}^{A H} O_{(m-1), L}^{H}+\sum_{H=1}^{\alpha} \varphi_{m}^{A J} O_{(L-1), m}^{J}
$$

From equation (5), the elements of $I_{(m)}^{W}$ and $R_{(m)}^{W}$ are represented as $L_{m}^{A H}$ and $\varphi_{m}^{A J}$ respectively. Then the element based on the output vector with respect to the arbitrary function is represented as,

$$
O_{(m, n)}^{A}=\sigma_{m}\left[I_{(m, n)}^{A}\right]
$$

From equation (6), the activation function is represented as $\sigma_{m}$. In general, there are different types of activation function, namely the sigmoid function, rectified linear unit function as well as logistic sigmoid function. The mathematical expressions for each respective function are mentioned as follows.

$$
\begin{array}{r}
\text { Sigmoid: } \sigma_{m}=\operatorname{Tan} H(I) \\
\text { Re L U: } \sigma_{m}=\operatorname{Max}(I, H) \\
\text { Logistic Sigmoid: } \sigma_{m}=\frac{1}{\left[1+e^{-I}\right]}
\end{array}
$$

Then the expression for the bias with respect to the output layer is determined as follows.

$$
O_{(m, n)}=\sigma_{m}\left[I_{(m)}^{W} O_{(m-1), L}+R_{(m)}^{W} O_{(L-1), m}\right]
$$

From equation (8), the output of the classifier is represented as $O_{(m, n)}$.

\section{Modified Sine Cosine Algorithm (MSCA)}

Sine Cosine Algorithm (SCA)

Mirjalili (2016) developed a novel Meta-heuristic algorithm named sine cosine algorithm that replicates the characteristics and behaviour of sine, cosine trigonometric functions. Followed by the random generation of position, the solutions are updated dynamically based on the command of a known global optimal solution. Then the evolutionary process of SCA and the updated equation in terms of both exploration and exploitation phase is represented in the following section.

$$
A_{X}^{T+1}=\left\{\begin{array}{l}
A_{X}^{T}+R_{1} \sin \left(R_{2}\right)\left|R_{3} Z_{X}^{T}-A_{X}^{T}\right| ; \text { If } R_{4}<0.5 \\
A_{X}^{T}+R_{1} \cos \left(R_{2}\right)\left|R_{3} Z_{X}^{T}-A_{X}^{T}\right| ; \text { If } R_{4} \geq 0.5
\end{array}\right.
$$

From equation (9):

$$
\begin{aligned}
& Z_{X}^{T}=\operatorname{ArgMin}\left\{F\left(Z_{X}^{T-1}\right), F\left(A_{X}^{T}\right), \ldots F\left(A_{L}^{T}\right)\right\} ; T \in[1, T] \\
& R_{1}=A-T \frac{A}{t}
\end{aligned}
$$

From equation (9), the random number is denoted by $R_{4}$ and the random values may range from $[0,1]$. Then the region of the next position that is present in between the destination and the solution is denoted by $R_{1}$; the movement outwards the destination is represented by $R_{2}$. The maximum iteration number and the current iterations are represented by tand $T$ respectively and the constant term is denoted as $A$.

\section{Modified Sine Cosine Algorithm (MSCA)}

Like various other evolutionary approaches, the sine cosine algorithm undergoes the defect of pre-mature convergence with complex and tricky optimisation issues. Therefore to overcome such shortcomings, the performances of the SCA are modified and enhanced by employing three various strategies: Quasi Opposition 
Learning, Elite-Guide progression, Adaptive Mutation. The mathematical formulation of each respective strategy is obtained in the following section.

\section{Strategy 1: Quasi Opposition Learning}

The quasi opposition based learning strategy is employed and acts as an effective tool to conquer the loss of population diversity due to the gathering of swarms. In addition, this strategy is also employed in enhancing the performance of the agent and in swarm diversification (Kumar Roy et al., 2013). Therefore, the swarm's global exploitation capability, which is to be enhanced, is formulated by:

$$
\begin{gathered}
B_{X, Y}^{T}=\left\{\begin{array}{c}
C_{Y}+R_{5}\left(C_{Y}-A_{X, Y}^{T}\right) ; \text { If } A_{X, Y}^{T}<C_{Y} \\
C_{Y}-R_{5}\left(A_{X, Y}^{T}-C_{Y}\right) ; \text { If } A_{X, Y}^{T} \geq C_{Y}
\end{array} ; \text { WhereX } \in[1, x], Y \in[1, y]\right. \\
C_{Y}=\frac{1}{2}\left[A_{Y}^{M A X}-A_{Y}^{M I N}\right]
\end{gathered}
$$

From equation (11), the $Y^{\text {th }}$ value of $X^{\text {th }}$ quasi opposition solutions at $T^{\text {th }}$ number of iteration is denoted as $B_{X, Y}^{T}$. Then the maximum and the minimum value of the $Y^{\text {th }}$ value is represented as $A_{Y}^{M A X}$ and $A_{Y}^{M I N}$ respectively. $\mathrm{Y}$ and $R_{5}$ signifies the total number of variables, and the random values range from $[0,1]$.

\section{$>$ Strategy 2: Elite-Guide progression}

In SCA, the evolutionary model utilises only the global optimal solution, whereas the elite agents are not taken into consideration which results in the convergence of local minimum value with very high probability. Therefore, in order to conquer such issues, the evolutionary mode in terms of the random weighting process is employed (Issa et al., 2018). The following mathematical equation provides a valuable solution that enhances the rate of convergence and search space, respectively. Thus,

$$
\begin{aligned}
& A_{X}^{T+1}=\left\{\begin{array}{l}
A_{X}^{T}+R_{1} \sin \left(R_{2}\right)\left|R_{3} Z_{X}^{T}-A_{X}^{T}\right| ; \text { If } R_{4}<0.5 \\
A_{X}^{T}+R_{1} \cos \left(R_{2}\right)\left|R_{3} Z_{X}^{T}-A_{X}^{T}\right| ; \text { If } R_{4} \geq 0.5
\end{array} \text { WhereX } \in[1, x], T \in[1, t]\right. \\
& Z_{X}^{T}=R_{6} Z_{X}^{T}+R_{7} W_{X}^{T}+R_{8} M_{X}^{T} ; \text { WhereX } \in[1, x], T \in[1, t] \\
& W_{X}^{T}=\operatorname{Arg} \operatorname{MiN}_{W_{X}^{T} \neq Z_{X}^{T}}\left\{F\left(Z_{X}^{T-1}\right), F\left(A_{X}^{T}\right), \ldots F\left(A_{L}^{T}\right)\right\} ; T \in[1, T] \\
& M_{X}^{T}=\operatorname{Arg} \underset{\substack{M \\
W_{X}^{T} \neq Z_{X}^{T} \\
W_{X}^{T} \neq M_{X}^{T}}}{ }\left\{F\left(Z_{X}^{T-1}\right), F\left(A_{X}^{T}\right), \ldots F\left(A_{L}^{T}\right)\right\} ; T \in[1, T]
\end{aligned}
$$

From the above equation, the second and third best optimal solution is represented by $W_{X}^{T}$ and $M_{X}^{T}$, respectively. $R_{6}, R_{7}, R_{8}$ Signifies the total number of variables and the random values ranges from $[0,1]$. Thus,

$$
R_{6}+R_{7}+R_{8}=1
$$

\section{Strategy 3: Adaptive Mutation}

In SCA, the current swarm fails to store the best optimal solution that further minimises the useful hidden information, and such issues can be conquered by employing an adaptive mutation strategy. In addition to this, a temporary swarm is developed by combining the modified evolution approach and quasi opposition learning approach. Therefore the updated equation by employing the adaptive mutation strategy is obtained as follows.

$$
\begin{gathered}
Q_{X}^{T}=\left\{\begin{array}{l}
N_{I N D E X}^{T}+a_{c}\left[Z_{X}^{T}-W_{X}^{T}\right] \operatorname{If}\left(S_{X} \geq \gamma\right) \\
G_{X}^{T} I f\left(S_{X}<\gamma\right)
\end{array}\right. \\
\text { Where } Z_{X}^{T}=\operatorname{ArgMin}\left\{F\left(Z_{X}^{T-1}\right), F\left(A_{X}^{T}\right), \ldots F\left(A_{L}^{T}\right)\right\}, X \in[1, x] \\
T \in[1, t], a_{c}=R_{9}+R_{10} * \underset{T}{=} \operatorname{and} S_{X}=\frac{\left|F\left(Z_{X}^{T}\right)\right|}{\sum_{X=1}^{X}\left|F\left(Z_{X}^{T}\right)\right|}
\end{gathered}
$$


From the above equation, the mutation solution with respect to the $T^{\mathrm{th}}$ number of iteration is denoted as $Q_{X}^{T}$. $a_{c}$ and $S_{X}$ signifies the adaptive coefficient and the coefficient in determining the activation of the mutation operator. $R_{9}, R_{10}$ signifies the total number of variables, and the random values range from $[0,1]$ and $[-0.9,0.1]$ respectively.

\section{Formation of DRNN-MSCA algorithm}

In this section, the DRNN, one of the machine learning approaches integrated with the modified sine cosine algorithm containing various three strategies, are developed to effectively predict risk with minimum time delay and cost. The execution procedure involved in forming the DRNN-MSCA is illustrated in the following section.

Step 1: The output obtained from the DRNN is provided as an input to the modified sine cosine algorithm. Here initially, the sizes of the swarm, maximum iteration numbers are defined, followed by the initialisation of the random population.

Step 2: Determine the objective function for the entire solution with respect to the problem that takes place during the position updated and during the evaluation of the optimal global solution.

Step 3: Followed by obtaining a global solution, the intermediate swarm is obtained by employing the quasi opposition learning strategy as mentioned in equation (11).

Step 4: Then, the off-spring swarm is determined by using Elite-Guide progression of equation (12) to (16).

Step 5: Setting a temporary swarm organised in an ascending order to obtain the best optimal solution. Then the adaptive mutation updated strategy is then employed based on equation (17) to generate the subsequent solutions for the next process.

Step 6: The iteration is stopped if the maximum iteration is met by achieving the optimal global solution. Else, return to step 2. Therefore the flow diagram for the formation of the DRNN-MSCA algorithm is represented in Fig. 3.

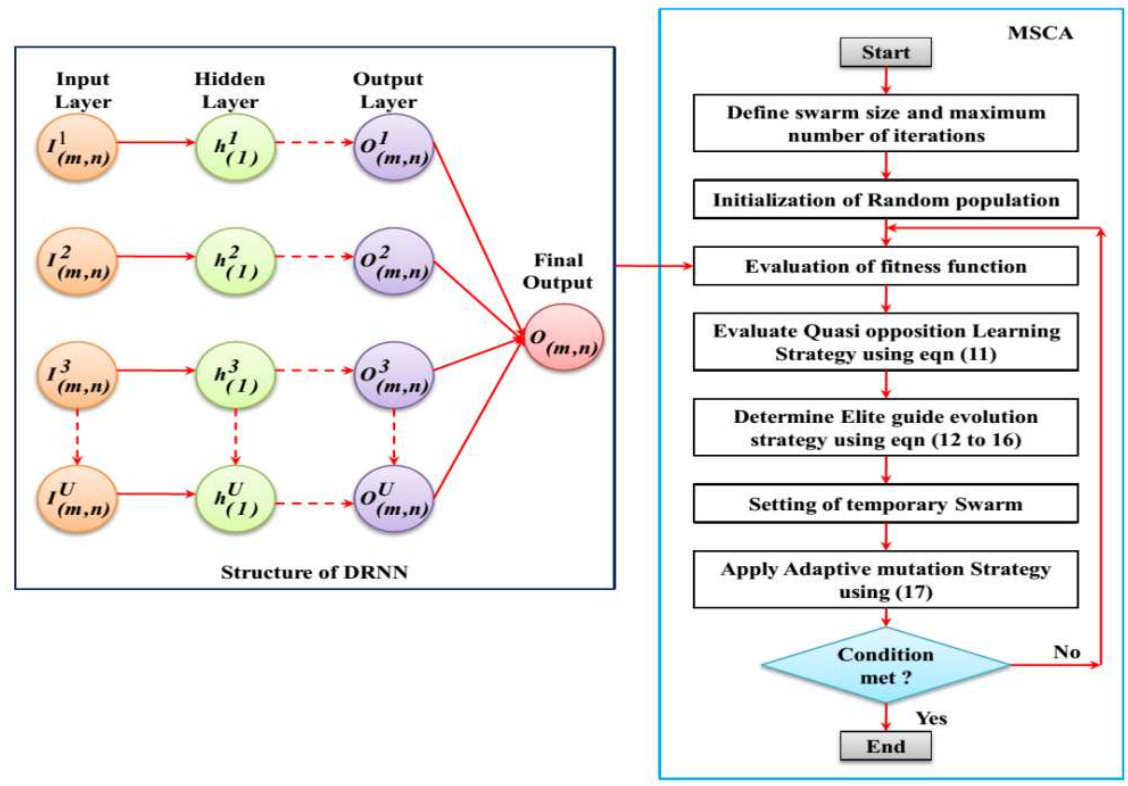

Fig.3. Formation of DRNN-MSCA algorithm

\section{Results and Discussion}

The questionnaires were distributed to resource person, proprietor and Construction contractor's responses from several organisation levels. The respondents who participated in the survey had many years of experience in treating several projects types. The respondent's characteristics that participated in the survey are reviewed in Table 4. Table 4 demonstrates that a maximum of the respondents $(54 \%)$ are working with the resource person organisation, about $35 \%$ of the respondents from the owner and $11 \%$ of the respondents from the Construction contractor. All the respondents had experience managing large projects, with $65 \%$ of respondents executed in Construction projects. The important number of respondents, i.e. $24 \%$ of the respondents, has executed more than 100 projects. In accordance with the response, $88 \%$ is achieved in dealing the Construction projects from various organisations. 
Tab. 4. Respondents statistics

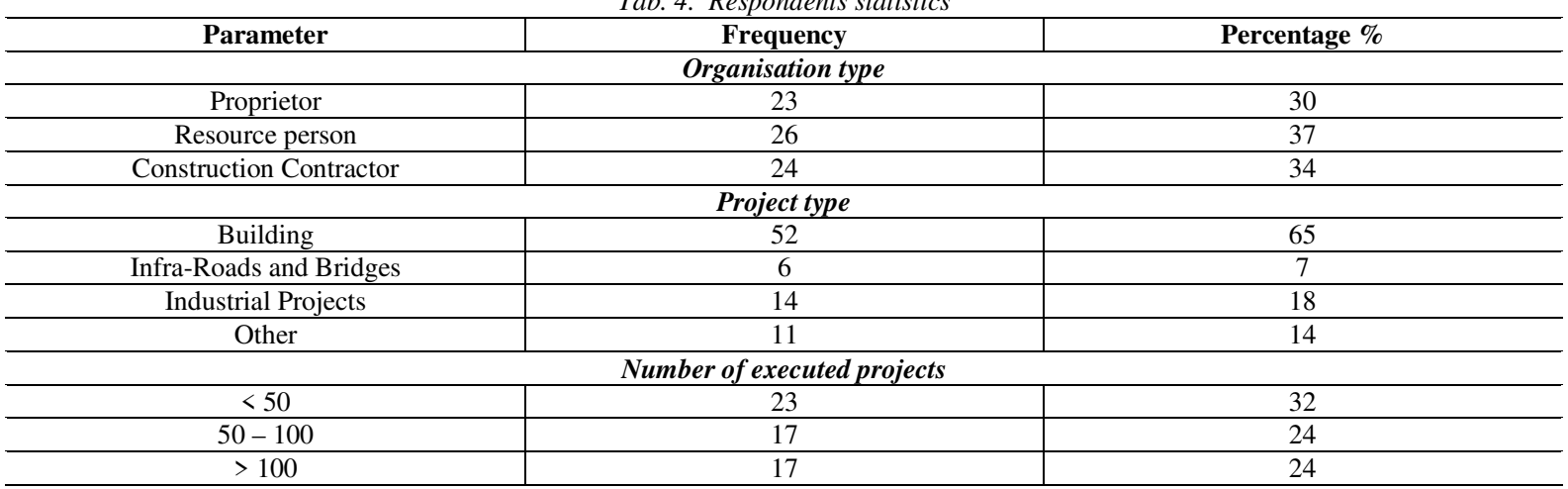

\section{Data collection}

The assembled data contained 100 completed projects with various degrees of time overrun. The gathered data consists of historical documents of earlier projects which were examined to separate the risk delay measurement in the construction projects. These documents consist of specifications, schedule baselines, contract documents and change order records. The data collection is completed by the arrangement and construction of the questionnaire survey. The respondent's characteristics that participated in the survey are reviewed in Table 5.

Every questionnaire form consists of a construction project and an additional ten variables. The first variable indicates the delay level, and the other nine variables refer to the risk delay sources in the construction project. Every risk source provided with scores depends on two scales. The first scale was the risk probability of occurring in the construction project. The second scale was the impact of the sources on the construction project. The second was linked to the sources on the construction project delay, as depicted in Table 5.

The entire risk impact was computed by multiplying the two scales. The Cronbach coefficient is utilised to calculate the inner consistency, and the value ranges from 0 to 1 . If the value of the coefficient is less than 0.3 so it cannot be accepted. Then the value of the reliability is low level. If the coefficient value is greater than 0.7 , it represents the consistency at a high level for the index table and can be highly accepted. For this analysis, the Cronbach is found to be 0.951 (Shanmugapriya \& Subramanian, 2013; Cindrela Devi \& Ananthanarayanan, 2017).

Tab. 5. Probability scales and risk delay impact in the construction projects

\begin{tabular}{c|c|c}
\hline \multicolumn{2}{c}{ Impact } \\
\hline Scale & Probability & 0.04 \\
Very low & 0.1 & 0.15 \\
Low & 0.25 & 0.25 \\
Medium & 0.55 & 0.45 \\
High & 0.75 & 0.85 \\
Very high & 0.95 & 0.5 \\
\hline
\end{tabular}

The probability and the variables impact were computed by the 5-point Likert scale by the measures from very low to a very high level. The input variables were categorised as very low, low, medium, high and very high. The output variables were classified into three classes. This method resulted in three kinds of delay levels which decreased the bias throughout the artificial intelligence execution model. Delay level was classified as: $<50 \%$ delay, $50-100 \%$ delay, and $>100 \%$ delay. The questionnaire was assigned to calculate the reliability of the questionnaire and to inspect the issues, and establish the items which are more confusing than the others. The result of Cronbach's alpha validates questionnaire reliability. The identified sources of risk are proprietor, resource person, Construction contractor, layout model, labour, stocks \& resources, apparatus, time \& delay, climate and external. The reliability test for the time and cost overruns is tabulated in Table 6.

Tab. 6. Reliability test for time and cost overruns

\begin{tabular}{c|c}
\hline Factors & Cronbach alpha \\
\hline Project-related & 0.718 \\
Responsibility of the contractor & 0.761 \\
Responsibility of the subcontractor & 0.701 \\
Responsibility of the consultant & 0.791 \\
Responsibility of the owner & 0.707 \\
Management condition & 0.856 \\
Design and Documentation & 0.789 \\
Economic circumstances & 0.304 \\
Materials & 0.832 \\
Environmental circumstances & 0.698 \\
Labour and equipment & 0.771 \\
Government relations & 0.887 \\
Financial groups & 0.725 \\
Construction parties & 0.826
\end{tabular}




\begin{tabular}{|c|c|}
\hline $\begin{array}{c}\text { Political groups } \\
\text { Constructional items }\end{array}$ & $\begin{array}{l}0.738 \\
0.736\end{array}$ \\
\hline Overall Cronbach alpha value & 0.951 \\
\hline
\end{tabular}

The most important factor that causes the construction cost overrun is based on the project life cycle and categorised as internal and external issues as depicted in Table 7. It is concluded that the important degree of agreement between the respondents for the cost overrun occurrence in the non-infrastructural Indian construction projects.

Tab. 7. The important factor for the causes of cost overrun

\begin{tabular}{|c|c|c|}
\hline Stage of the project & Internal issues & External issues \\
\hline Pre-planning stage & Financial issues & Regularity approval delays \\
\hline $\begin{array}{l}\text { Planning \& layout model } \\
\text { stage }\end{array}$ & $\begin{array}{c}\text { Scope creep } \\
\text { Layout model/ alterations in the specification } \\
\text { A deprived assortment of resource person } \\
\text { Unsuccessful acquisition planning }\end{array}$ & $\begin{array}{c}\text { Alterations in-laws and dictatorial } \\
\text { structure } \\
\text { Political difficulties } \\
\text { Unexpected site situations }\end{array}$ \\
\hline Execution and supervising & $\begin{array}{c}\text { Rework } \\
\text { Inefficient planning \& supervising } \\
\text { Construction delays } \\
\text { Delay in opinion-making } \\
\text { Contractual arguments }\end{array}$ & Inflation/ price fluctuations \\
\hline
\end{tabular}

\section{Performance evaluation}

The performance evaluation of the predicted method was computed by the class performance and the entire performance measures. The performance is evaluated for three different metrics, namely precision, sensitivity and specificity. The entire performance of the predicted model is computed by using accuracy and classification error. Confusion matrices are the particular table that is capable of depicting the classification model performance. The confusion matrixes for the proposed DRNN-MSCA approach are shown in Table 8, in which the classifiers are primarily organised to train the whole dataset. The confusion matrix consists of an integer that reflects the counts of assured classifications.

Tab. 8. Confusion matrix for DRNN-MSCA classifications

\begin{tabular}{|c|c|c|c|c|}
\hline \multicolumn{5}{|c|}{ Predicted Class } \\
\hline Actual class & $<50 \%$ Delay & $50-100 \%$ Delay & $>100 \%$ Delay & Totals \\
\hline$<50 \%$ Delay & 18 & 5 & 2 & 25 \\
\hline $50-100 \%$ Delay & 0 & 15 & 1 & 16 \\
\hline$>100 \%$ Delay & 2 & 2 & 9 & 13 \\
\hline Totals & 20 & 22 & 12 & - \\
\hline
\end{tabular}

The entire accurate predictions are situated in the diagonal of the table, and this assists the visual inspection of the error matrix, that is, any nonzero values outside the diagonal. Some key terms for the classifier need to be clarified first before computing the model performances from the matrices.

True positives (Tp): Prediction numbers that are precisely assigned to the class (i.e., matrix diagonal value for the respective class).

False positives (Fp): Prediction numbers that are mistakenly assigned to the class (i.e., the sum of values in the respective class column apart from the Tp).

False negatives (Fn): Prediction numbers that was mistakenly unidentified as the class assignments (i.e., the sum of values in the respective class row apart from the Tp).

True negatives (Tn): prediction numbers that were precisely identified as not intimacy to the class (i.e., the sum of values of the entire rows and columns excluding the row and column of that particular class).

The two model entire performance indices utilised in this research are accuracy and misclassification error. Accuracy is the percentage of the total number of accurate classifications to the total number of predicted classifications by the model, and likewise, the misclassification error is the percentage of the straight misclassifications. The entire accuracy is recognised as the ratio among the sum of diagonal values and the sum of the table. Hence, the confusion matrix of the model has high numbers in the diagonals and small numbers other than the diagonal values. The performance evaluation consists of a precision, specificity, sensitivity, false-positive rate and false-negative rate are computed from the confusion matrices as shown in the below equations correspondingly.

$$
\begin{gathered}
\text { Precision }=\frac{T_{p}}{T_{p}+F_{p}} \\
\text { Specificity }=\frac{T_{n}}{T_{n}+F_{p}}
\end{gathered}
$$




$$
\begin{gathered}
\text { Sensitivity }=\frac{T_{p}}{T_{p}+F_{n}} \\
F_{p r}=\frac{F_{p}}{F_{p}+T_{n}} \\
F_{n r}=\frac{F_{n}}{T_{p}+F_{n}} \\
\text { Accuracy }=\frac{T_{p}+T_{n}}{T_{p}+F_{p}+T_{n}+F_{n}} \\
\text { Classification error }=1-\text { accuracy }
\end{gathered}
$$

The examination of the gathered data based on 100 projects was conducted to predict the sources of delay issues efficiently. The properties of the data compiled and delay sources distributions among the construction projects are demonstrated in Fig 4.

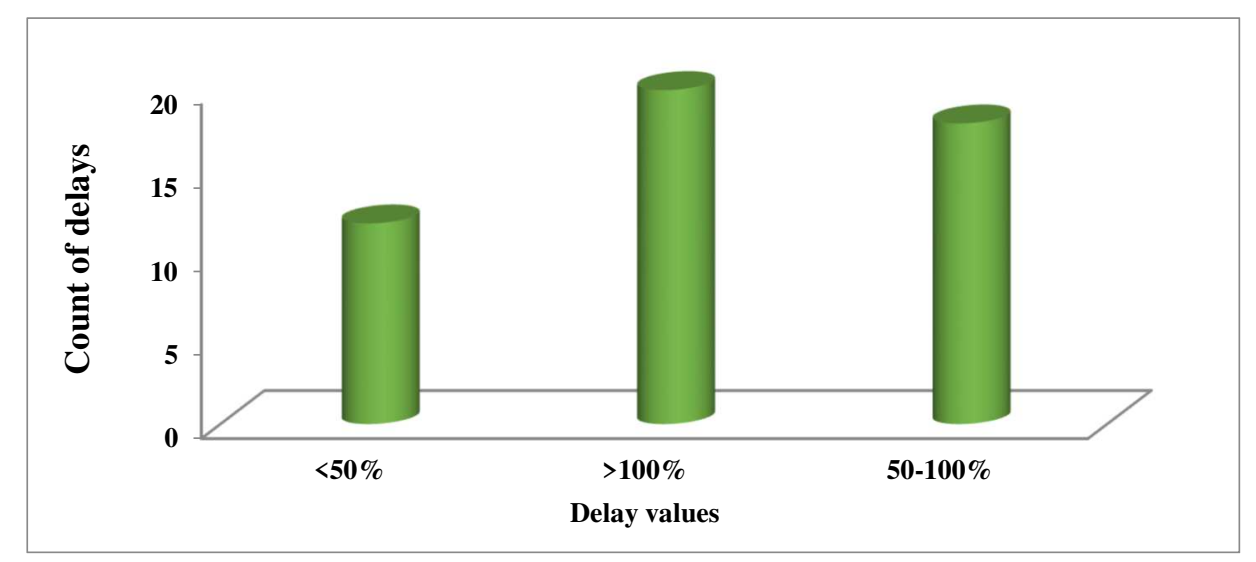

Fig.4. Frequency delay counts in the construction project

Depending upon the reported results, Fig 5 shows the project counts by $<50 \%$ delay, $50-100 \%$ delay and $>$ $100 \%$ delay were $12(30 \%), 18(40 \%)$ and $20(50 \%)$ correspondingly. From this, it can be observed that a high percentage of the projects associates with $>100 \%$ delay class. Fig 5 illustrates the delay source distribution between every delay class problem that was achieved from the past records, pilot study and distributed questionnaire. These results exposed the delay sources values of the Construction contractor, proprietor, resource person, time and external factors have more impact than the other sources of delay. Proprietor, resource person, Construction contractor, and project are indicated as the internal risk sources that impact the project delay. External factors are discussed by the particular conditions which are experienced in the study area in a way that strictly affects the construction industry. These circumstances have a massive impact on project stockholders and project performance. Contrastingly, the application of the robust predictive method can donate to estimate an exact duration in the construction projects and examine delay risk sources that arise from the dynamic and complex nature of the construction region. 


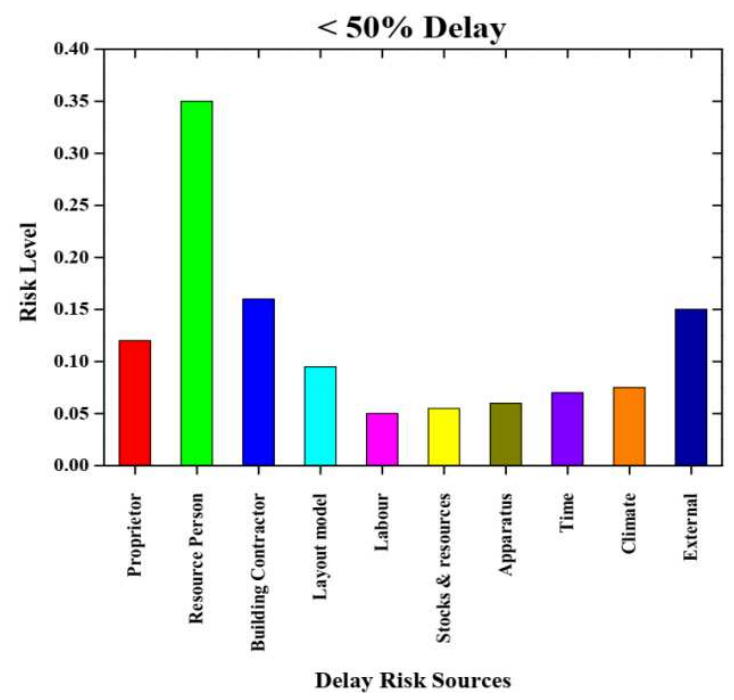

(a)

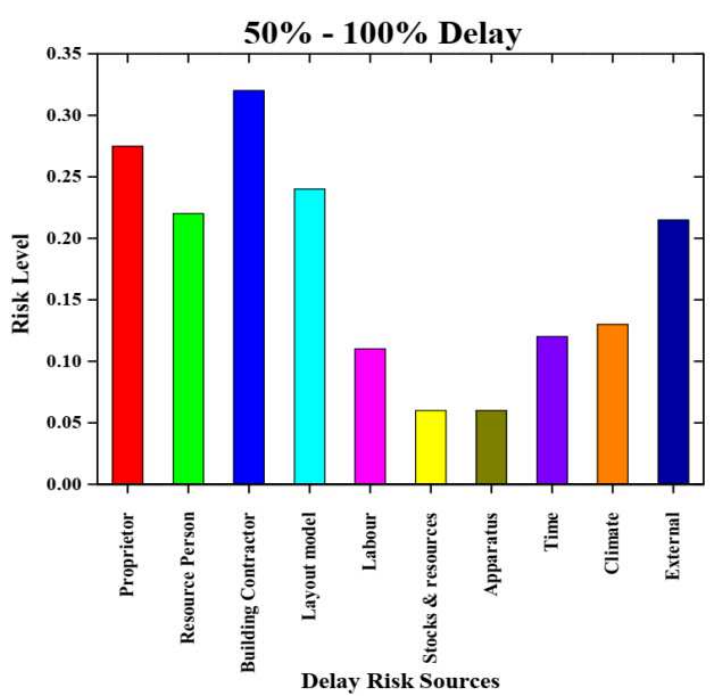

(b)

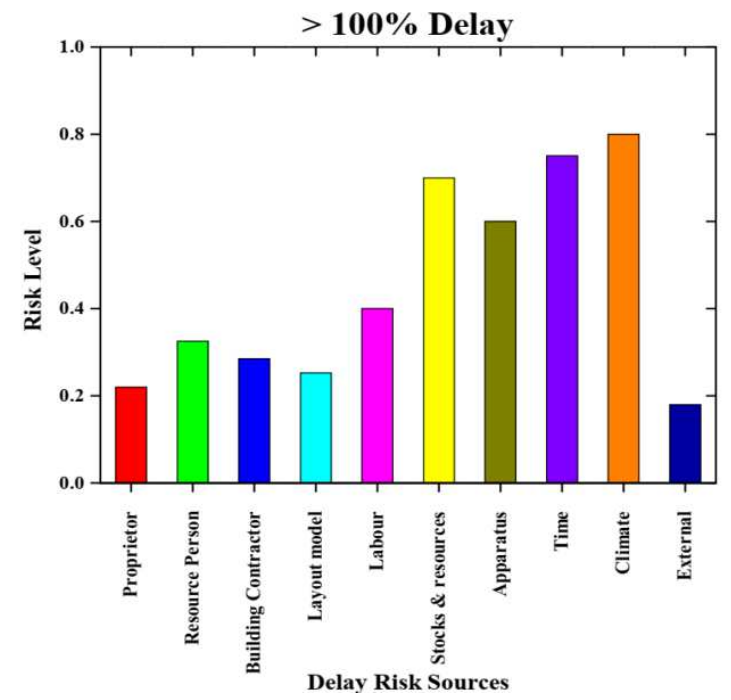

(c)

Fig. 5. (a) Delay sources distribution for the projects with class $<50 \%$ (b) Delay sources distribution for the projects with class 50 $100 \%$ (c) Delay sources distribution for the projects with class $>100 \%$

Table 9 shows the comparison of accuracy and misclassification error between the various classifiers such as ANN, RF-GA and ML with the proposed approach DRNN-MSCA. The performance measures are computed for both the training as well as the testing. It can be concluded that the proposed approach performs well in both the training as well as the testing process.

Tab. 9. Comparison of various classifiers for accuracy and misclassification error

\begin{tabular}{ccccc}
\hline Performance metrics & $\boldsymbol{A N N}$ & $\boldsymbol{R F}-\boldsymbol{G A}$ & $\boldsymbol{M L}$ & DRNN-MSCA \\
\hline Accuracy & $73.58 \%(43.5 \%)$ & $75.84 \%(45.8 \%)$ & $76.45 \%(48.5 \%)$ & $81.65 \%(52.9 \%)$ \\
Misclassification error & $28.61 \%(54.9 \%)$ & $25.42 \%(52.4 \%)$ & $23.54 \%(50.5 \%)$ & $21.54 \%(45.2 \%)$ \\
\hline
\end{tabular}

The visual interpretations of the model performance by the classifiers are plotted in Fig 6 . The performance of the various classifiers such as ANN (Alias et al., 2015), RF-GA (Yaseen et al., 2020; Gondia et al., 2020) is compared with the proposed DRNN-MSCA approach is shown in Fig 6. The overall prediction performance of the proposed approach is high. The value of the metrics such as precision, sensitivity, specificity, false-positive rate and false-negative rate for the proposed classifier is high when compared with other classifiers. 


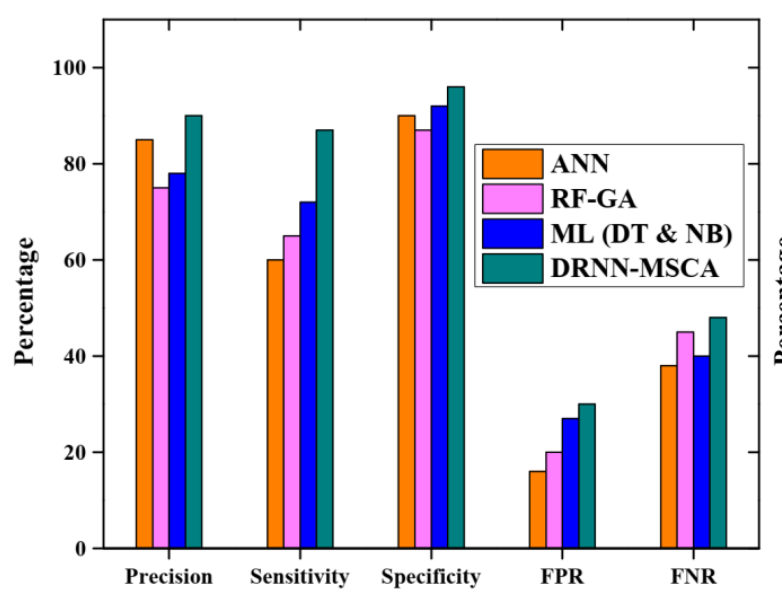

(a)

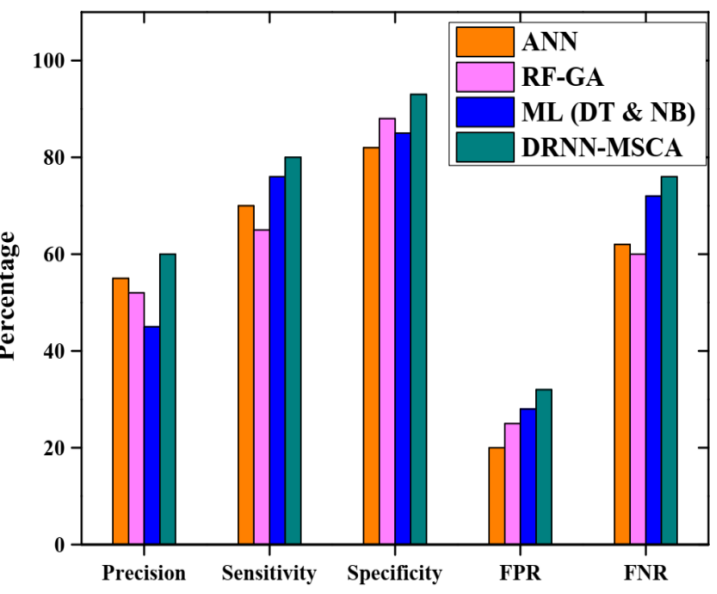

(b)

Fig.6. Comparison of classifiers for (a) training and (b) testing performances

\section{Conclusion and Future Scope}

At the present time, project management has been utilised extensively across numerous industrial sectors. Numerous surveys demonstrated by various research scholars were conducted between the managerial personnel, engineers and contractors to analyse the risk while constructing projects. The organisation's main intention is to identify the risk and implement various corrective measures to mitigate various potential impacts associated with them. This paper proposed five major phases, namely the Identification of risk source and its factors, Systemization and Pre-processing of the dataset, Analysis of dataset constraints, Sensitivity data computation, and Tool selection using DRNN-MSCA. The initial phase involves the determination of appropriate risk factors and their sources, namely Proprietor, Resource Person, Construction Contractor, Layout model, Labour, Stocks and Resources, Apparatus, Time Delay and Cost, Climate as well as External Risk. The second phase predicts developing the predictive tool analysis comprises 100 construction projects from 48 firms that experience diverse degrees of time delay. The dataset analysis and sensitivity data are computed in the third and fourth phases. The fifth phase comprises of Tool selection using DRNN-MSCA to determine the risk, thereby establishing an effective and accurate prediction analysis. Finally, the performance of the proposed approach is calculated and compared with a few other existing approaches such as ANN, RF-GA, and ML. The experimental analyses are conducted, and the results reveal that the proposed approach provides superior performance with less cost and time delay. The limitation of this work is that 100 construction projects have been identified carefully and evaluated risk, and these 100 construction projects are highly correlated with the time and money. However, the accuracy and error will be changed based on the selection of projects and numbers. The existing approaches were analysed with our proposed techniques. It was achieved around $81.65 \%$. In future, non-correlative construction projects could be identified and evaluated. This suggestion work is to be compared with other traditional approaches and modern approaches.

\section{References}

Abazid, M., \& Harb, H. (2018). An Overview of Risk Management in The Construction Projects. Academic Research International, 9(2), 73-79.

Adeleke, A. Q., Bahaudin, A. Y., Kamaruddeen, A. M., Bamgbade, J. A., Khan, M. W. A., Panda, S., \& Afolabi, Y. A. (2019). An empirical analysis of organizational external factors on construction risk management. International Journal of Supply Chain Management, 8(1), 933-940.

Alias, M., Dhanya, R., \& Ramasamy, G. (2015). Study on factors affecting the performance of construction projects and developing a cost prediction model using ANN. International Journal of Earth Sciences and Engineering, 8(5), 2189-2194.

Al-Subaie, A.A., Faisal, M.N., Aouni, B., Jabeen, F. (2021). Investigating the role of leadership styles and governance on project performance in megaprojects. Polish Journal of Management Studies, 23 (1), 45-58. https://doi.org/10.17512/pjms.2021.23.1.03

Bacik, R., Fedorko, R., Abbas, E. W., Rigelsky, M., Ivankova, V., \& Obsatnikova, K. (2019). The impact of selected quality management attributes on the profitability of TOP hotels in the Visegrad group countries. 
Polish Journal of Management Studies, 19(1), 46-58. https://doi.org/10.17512/pjms.2019.19.1.04

Bhatt, D., Danalakshmi, D., Hariharasudan, A., Lis, M., \& Grabowska, M. (2021). Forecasting of Energy Demands for Smart Home Applications. Energies, 14(4). https://doi.org/10.3390/en14041045

Bu Qammaz, A. S., \& AlMaian, R. Y. (2020). A critical success factors model for effective implementation of risk management process in the construction projects. Journal of Engineering Research (Kuwait), 8(3), 50-70. https://doi.org/10.36909/JER.V8I3.7877

Burduk, A., Cek, D. W. I. E.., Tlach, V., Ságová, Z., \& Ska, J. K. Ń. (2021). Risk assessment of horizontal transport system in a copper mine. Acta Montanistica Slovaca, 26(26), 303-314. https://doi.org/10.46544/ams.v26i2.09

Chatterjee, K., Zavadskas, E. K., Tamošaitiene, J., Adhikary, K., \& Kar, S. (2018). A hybrid MCDM technique for risk management in construction projects. Symmetry, 10(2). https://doi.org/10.3390/sym10020046

Cindrela Devi, A., \& Ananthanarayanan, K. (2017). Factors influencing cost over-run in Indian construction projects. MATEC Web of Conferences, 120, 1-8. https://doi.org/10.1051/matecconf/201712002023

Dvorsky, J., Belas, J., Gavurova, B., \& Brabenec, T. (2021) Business risk management in the context of small and medium-sized enterprises. Economic Research-Ekonomska Istraživanja, 34(1), 1690-1708. https://doi.org/10.1080/1331677X.2020.1844588

Enshassi, M. S. A., Walbridge, S., West, J. S., \& Haas, C. T. (2019). Integrated Risk Management Framework for Tolerance-Based Mitigation Strategy Decision Support in Modular Construction Projects. Journal of Management in Engineering, 35(4), 05019004. https://doi.org/10.1061/(asce)me.1943-5479.0000698

Fakhratov, M., Chulkov, V., Kuzhin, M., \& Akbari, M. S. (2020). Risk Management implementation and presenting the applicable methodology for its implementation in construction projects. E3S Web of Conferences, 164. https://doi.org/10.1051/e3sconf/202016410014

Gavurova, B., Belas, J., Zvarikova, K., Rigelsky, M., \& Ivankova, V. (2021a). The effect of education and R\&D on tourism spending in OECD countries: An empirical study. Amfiteatru Economic, 23(58), 806-823. https://doi.org/10.24818/EA/2021/58/806

Gavurova, B., Belas, J., Valaskova, K., Rigelsky, M., \& Ivankova, V. (2021b). Relations between infrastructure innovations and tourism spending in developed countries: A macroeconomic perspective. Technological and Economic Development of Economy, 27(5), 1072-1094. https://doi.org/10.3846/tede.2021.15361

Gondia, A., Siam, A., El-Dakhakhni, W., \& Nassar, A. H. (2020). Machine Learning Algorithms for Construction Projects Delay Risk Prediction. Journal of Construction Engineering and Management, 146(1), 04019085-1-16. https://doi.org/10.1061/(asce)co.1943-7862.0001736

Hamzaoui, F., Amine Allal, M., Taillandier, F., \& Achoui, M. (2019). Risk management in construction projects by coupling the SMACC agent with the MADS MOSAR method-application to the dam project in Mascara, Algeria. International Journal of Construction Management, 2019-2022. https://doi.org/10.1080/15623599.2019.1641890

Issa, M., Hassanien, A. E., Oliva, D., Helmi, A., Ziedan, I., \& Alzohairy, A. (2018). ASCA-PSO: Adaptive sine cosine optimization algorithm integrated with particle swarm for pairwise local sequence alignment. Expert Systems with Applications, 99, 56-70. https://doi.org/10.1016/j.eswa.2018.01.019

Jiř́čck, P., Dostálová, Z. (2018). Financing Innovation, Neo-Schumpeterian Theory and the Reduction of Regional Disparities in the European Union. Littera Scripta, 11(2), 95-105.

Kasych, A., Vochozka, M. (2018). Methodical Support of the Enterpries Sustainable Development Management. Marketing and Management of Innovations, 1, 371-381. https://doi.org/ 10.21272/mmi.2018.1-29

Kliestik, T., Nica, E., Šuleř, P., Valášková, K. (2020). Innovations in the Compan's Earnings Management: The Case for the Czech Republic and Slovakia. Marketing and Management of Innovations, 3, 332-345. https://doi.org/ 10.21272/mmi.2020.3-24

Krantikumar Mhetre, B.A.Konnur, Amarsinh, A. B. L. (2016). Risk Management in Construction Industry. International Journal of Engineering Research, 5(1), 153-155. https://doi.org/10.15373/2249555x/june2013/125

Krulický, T., Kalinová, E., Kučera, J. (2020). Machine Learning Predicition of USA Export to PRC in Context of Mutual Sanction. Littera Scripta, 13(1), 83-101. https://doi.org/10.36708/Littera_Scripta2020/1/6

Krulický, T., Horák, J. (2019). Real estate as an investment asset. In Horák, J. (Ed.) Innovative Economic Symposium 2018 - Milestones and Trends of World Economy (IES2018), China, Bejing, 8. - 9. 11. 2018. SHS Web of Conferences, 61, Art. No. 01011. https://doi.org/ 10.1051/shsconf/20196101011

Kumar Roy, P., Sur, A., \& Pradhan, D. K. (2013). Optimal short-term hydro-thermal scheduling using quasioppositional teaching learning based optimization. Engineering Applications of Artificial Intelligence, 26(10), 2516-2524. https://doi.org/10.1016/j.engappai.2013.08.002

Lam, T. Y. M., \& Siwingwa, N. (2017). Risk management and contingency sum of construction projects. Journal of Financial Management of Property and Construction, 22(3), 237-251. https://doi.org/10.1108/JFMPC10-2016-0047

Leslie Appiah, B. (2020). Risk Management Processes and Analysis in Projects Construction Industry. Journal of 
Civil, Construction and Environmental Engineering, $\quad 52$. https://doi.org/10.11648/j.jccee.20200504.14

Mahmoudi, A., Abbasi, M., Deng, X., Ikram, M., \& Yeganeh, S. (2020). A novel model for risk management of outsourced construction projects using decision-making methods: a case study. Grey Systems: Theory and Application, 10(2), 97-123. https://doi.org/10.1108/gs-09-2019-0038

Mirjalili, S. (2016). SCA: A Sine Cosine Algorithm for solving optimization problems Seyedali. Knowledge-Based Systems, 96, 120-133. https://doi.org/10.1109/ACCESS.2021.3058128

Mustaffa, N. K., Isa, C. M. M., Joseph, V. R. A., \& Aziz, M. F. H. A. (2020). A 3d bim integration in risk management for construction projects in malaysia. Proceedings of the International Conference on Industrial Engineering and Operations Management, August, 2351-2364.

N.P.Srinivasan, A. R. (2020). Study on Factors Influencing Risk Management in Construction Projects. Adalya Journal, 9(1), 408-410.

Nawaz, A., Waqar, A., Shah, S. A. R., Sajid, M., \& Khalid, M. I. (2019). An innovative framework for risk management in construction projects in developing countries: Evidence from Pakistan. Risks, 7(1). https://doi.org/10.3390/risks7010024

Pune Borhade, R. R., \& Nagmode, M. S. (2020). Modified Atom Search Optimization-based Deep Recurrent Neural Network for epileptic seizure prediction using electroencephalogram signals. Biocybernetics and Biomedical Engineering, 40(4), 1638-1653. https://doi.org/10.4018/IJACI.2021070108

Rahman, M. S., \& Adnan, T. M. (2020). Risk management and risk management performance measurement in the construction projects of Finland. Journal of Project Management, 5, 167-178. https://doi.org/10.5267/j.jpm.2020.5.001

Rowland, Z., Šuleř, P. (2019). Quality Culture: a Tool of Financial Managemetnto Reduce Risk. In Popa, I., Dobrin, C., Ciocoiu, C. N. (Eds.) Proceedings of the $13^{\text {th }}$ International Management Conference: Management Strategies for High Performance (IMC 2019), Romania, Bucharest, 31. 10. - 1. 11. 2019. 730-737.

Shanmugapriya, S., \& Subramanian, K. (2013). Investigation of Significant Factors Influencing Time and Cost Overruns in Indian Construction Projects. International Journal of Emerging Technology and Advanced Engineering, 3(10), 734-740.

Siwiec, D., Pacana, A. (2021). Method of improve the level of product quality. Production Engineering Archives, 27 (1), 1-7. https://doi.org/10.30657/pea.2021.27.1

Shojaei, P., \& Haeri, S. A. S. (2019). Development of supply chain risk management approaches for construction projects: A grounded theory approach. Computers and Industrial Engineering, 128, 837-850. https://doi.org/10.1016/j.cie.2018.11.045

Tixier, A. J. P., Hallowell, M. R., Rajagopalan, B., \& Bowman, D. (2017). Construction Safety Clash Detection: Identifying Safety Incompatibilities among Fundamental Attributes using Data Mining. Automation in Construction, 74, 39-54. https://doi.org/10.1016/j.autcon.2016.11.001

Uğural, M. N., Giritli, H., \& Urbański, M. (2020). Determinants of the turnover intention of construction professionals: A mediation analysis. Sustainability (Switzerland), 12(3). https://doi.org/10.3390/su12030954

Vaněk, M., Valverde, G. F., Černý, I., \& Hudeček, V. (2020). Coal handling operational risk management: Stripped overburden transport in brown coal open pit mines. Acta Montanistica Slovaca, 25(2), 170-181. https://doi.org/10.46544/AMS.v25i2.4

Vaníčková, R., \& Szczepańska-Woszczyna, K. (2020). Innovation of business and marketing plan of growth strategy and competitive advantage in exhibition industry. Polish Journal of Management Studies, 21(2), 425-445. https://doi.org/10.17512/pjms.2020.21.2.30

Vrbka, J., Šuleř, P., Machová, V., Horák, J. (2020). Evaluation of Performance of MLP Neural Networks and RBF Neural Networks in Adjusting Time Series of the Development of the Trade Balance between the USA and the PRC. Littera Scripta, 13(2), 23-38. https://doi.org/10.36708/Littera_Scripta2020/2/3

Vrbka, J., Šuleř, P., Horák, J. (2019). Analysis of Companies operating in the Construction Industry in the Czech Republic Based on Kohonen Networks - Identification of Leaders in the Field. In Dvouletý, O., Lukeš, M., Misar, J. (Eds.) Proceedings of the $7^{\text {th }}$ International Conference Innovation Management, Entrepreneurship and Sustainability (IMES 2019), Czech Republic, Prague, 30. 31. 5. 2019. 1017-1028.

Velumani, P., Nampoothiri, N. V. N., \& Mariusz, U. (2021). A comparative study of models for the construction duration prediction in highway road projects of India. Sustainability, 13(8). https://doi.org/10.3390/su13084552

Wang, T., Gao, S., Li, X., \& Ning, X. (2018). A meta-network-based risk evaluation and control method for industrialized building construction projects. Journal of Cleaner Production, 205, 552-564. https://doi.org/10.1016/j.jclepro.2018.09.127

Wolniak, R. (2019). Problems of use of FMEA method in industrial enterprise. Production Engineering Archives, 23, 12-17. https://doi.org/10.30657/pea.2019.23.02 
Xia, N., Zhong, R., Wu, C., Wang, X., \& Wang, S. (2017). Assessment of Stakeholder-Related Risks in Construction Projects: Integrated Analyses of Risk Attributes and Stakeholder Influences. Journal of Construction Engineering and Management, 143(8), 04017030. https://doi.org/10.1061/(asce)co.19437862.0001322

Yaseen, Z. M., Ali, Z. H., Salih, S. Q., \& Al-Ansari, N. (2020). Prediction of risk delay in construction projects using a hybrid artificial intelligence model. Sustainability, 12(4), 1-14. https://doi.org/10.3390/su12041514

Yazdani, M., Abdi, M. R., Kumar, N., Keshavarz-Ghorabaee, M., \& Chan, F. T. S. (2019). Improved Decision Model for Evaluating Risks in Construction Projects. Journal of Construction Engineering and Management, 145(5), 04019024. https://doi.org/10.1061/(asce)co.1943-7862.0001640

Zhang, X., \& Mohandes, S. R. (2020). Occupational Health and Safety in green building construction projects: A holistic Z-numbers-based risk management framework. Journal of Cleaner Production, 275, 2-4. https://doi.org/10.1016/j.jclepro.2020.122788 